\title{
ADORNO, ARTE E EDUCAÇÃO: NEGÓCIO DA ARTE COMO NEGAÇÃO
}

\author{
Luiz Hermenegildo Fabiano*
}

\begin{abstract}
RESUMO: O eixo temático desta investigação trata de compreender que a obra de arte corporifica na sua forma interna uma autonomia relativa com relação à realidade empírica sobre a qual se torna reflexão crítica. Ao se caracterizar como mediação com a realidade social que a produziu, a arte é por isso mesmo a sua negação. É esse princípio de negação determinada, em que se condensam na obra de arte as antinomias e os antagonismos como antíteses da sociedade enquanto problema de sua forma interna, o elemento ao qual Theodor W. Adorno atribui dimensão epistemológica. Nessa categoria do conhecimento assim concebida, pela perspectiva estética, a razão instrumental como práxis brutal da sobrevivência é concretamente questionada na sua forma restritiva de conhecimento.
\end{abstract}

Palavras-chave: Arte. Estética. Mediação. Negação. Razão instrumental.

\section{ADORNO, ART AND EDUCATION: ART BUSINESS AS NEGATION}

ABSTRACT: The main investigation in this paper aims at understanding that a work of art in its internal form gets a relative autonomy from the empiric reality of which it becomes a critical reflection. As mediation to the social and historical reality that produced it, art is characterized as a negation of this same reality. This principle of determined negation as an antithesis of society is condensed in a work of art as the problem of its internal form, an element to which Theodor W. Adorno conferred an epistemological dimension. In this category of knowledge, considered through the aesthetics perspective, the instrumental reason as a brutal praxis of surviving is concretely questioned in its restrictive form of knowledge.

Key words: Art. Aesthetics. Mediation. Negation. Instrumental reason.

Doutor em Fundamentos Históricos e Filosóficos da Educação, professor de Métodos e Técnicas de Pesquisa da Universidade Estadual de Maringá (UEM-PR).

Educ. Soc., Campinas, vol. 24, n. 83, p. 495-505, agosto 2003

Disponível em <http://www.cedes.unicamp.br> 
processo de massificação cultural, tendo-se em mente o conceito de indústria cultural ${ }^{1}$ pelo imediatismo de sua expressão, não expressa conteúdos culturais como processo civilizatório e, portanto, de autonomia do indivíduo. Muito pelo contrário, os produtos culturais (se é que assim se possa designálos) veiculados no contexto da sociedade de massa, embora contenham elementos de cultura, não é essa a finalidade ou função que os constitui. O cerne, isto é, o núcleo que dá sustentação a essa forma cultural apropriada ideologicamente é a dinâmica consumista consolidada pelo processo industrial como universo social unidimensionalizado.

Obviamente, não se pretende aqui relegar a importância ou a própria historicidade na qual o processo de industrialização ocorre, mas evidenciar que, concomitantemente a essa conquista técnica e humana, o seu desenvolvimento resulta num interesse exclusivo dos aspectos técnico-comerciais, em detrimento do desenvolvimento social e humano. A cultura, nesse ambiente social industrializado, tem por alvo não o indivíduo ou a construção de sujeitos, mas exatamente a sua objetificação, para reificá-lo no processo de produção.

Ao se tomar por princípio que o sistema da indústria cultural reorienta as massas, pouco lhes permitindo a evasão do cerco que exerce ao lhes impor esquemas de comportamento, os quais exploram a fraqueza do ego social, justifica-se compreender criticamente os seus mecanismos ardilosos. Pois "o encorajamento e a exploração da fraqueza do eu, à qual a sociedade atual, com sua concentração do poder, condena de toda maneira seus membros" (Cohn, 1994, p. 94), levam a consciência a um estado regressivo.

A negação do pensamento, a diversão como resignação e estar de acordo com o sempre igual e semelhante como um princípio de identidade se torna elemento central de sustentação desse sistema industrial, já que é sua cria. O princípio da identidade, consubstanciado nessa estrutura social como justificativa e confirmação, é o processo pelo qual o conceito se iguala à coisa. Assim, a ideologia cristaliza-se e impõe-se como modelo de verdade existencial pelos valores que inculca, estabelecendo-se como modelo de realidade indiscernível.

A partir do fato de que o embrutecimento e a regressão dos sentidos humanos pelo processo de produção e reprodução desse 
sistema social constituem a entropia da subjetividade, Adorno busca na estética contemporânea a viabilidade de um resgate da percepção dos sentidos. O caráter de não-identidade e de não-imediaticidade da arte moderna é que Adorno vai diferenciar como traço de sobrevivência estética com relação aos fetiches totalitários inculcados pela indústria cultural.

O entendimento do qual se parte, tomando-se a acepção adorniana, é o de que a obra de arte não estabelece uma identificação imediata, mas de mediação com a realidade social que a produziu. Assim entendida, ela se corporifica na sua forma interna, de uma autonomia relativa com relação à realidade empírica sobre a qual se torna reflexão crítica e negação. É esse princípio de negação determinada, em que se condensam na obra de arte as antinomias e os antagonismos como antíteses da sociedade enquanto problema de sua forma interna, o elemento ao qual Adorno atribui dimensão epistemológica. Nessa categoria de conhecimento assim concebida, pela perspectiva estética, a razão instrumental como práxis brutal da sobrevivência é concretamente questionada na sua forma restritiva de conhecimento. E se a dimensão estética da obra artística por si só não se constitui como determinante de mudança das condições sociais, nela está contida pelo menos a possibilidade de articular tais mudanças, tomando-se por base a mediação com a realidade histórico-social que a produziu, sem contudo ser a sua afirmação. Mas, contrariamente, a forma pela qual uma obra artística é estruturada acaba por estabelecer a negação de si mesma como expressão imediata da realidade empírica na qual fora gerada. Essa negatividade empírica é que a torna o ser que é e lhe confere a autonomia pela qual a realidade social é mediada.

Tal negatividade está consubstanciada, entretanto, nas concepções teóricas mais amplas de Adorno no tocante à natureza da relação entre teoria e transformação social. Buck-Mors, em Origen de la dialéctica negativa, ao admitir que Adorno jamais explicou de todo tal relação, comenta que "parece claro que veía en la negatividad crítica una fuerza creativa en sí misma, creía que través de su propria fuerza podía al menos alcanzar el conocimiento de la verdad, y que la transformación resultante en la 'conciencia' conduciría de algún modo a la praxis social” (Buck-Mors, 1981, p. 92).

O caráter de negatividade e de não-identidade da obra artística como negação plena do conteúdo social, isto é, "negação 
determinada" na conceituação de Adorno, potencializa a arte como conhecimento crítico da sociedade. Sua fruição não se dá por mero consumo ou por ser coisa desfrutável, mas numa relação de apropriação da sua lógica interna, da sua lei formal, elementos pelos quais se dão as injunções sociais que na obra de arte estão mediadas.

Diferentemente dessa condição, nos produtos da indústria cultural a própria imediaticidade com que os bens culturais se identificam com a lógica do mercado de forma absolutizada torna o processo de mediação inviável. E isso ocorre em razão de as injunções sociais que aí se operam serem explicitadas tão direta e mecanicamente que acabam não se convertendo na forma da obra. O produto estético formaliza uma lógica própria e particular que ao mesmo tempo se descola da logicidade do real que o produziu e, embora não seja a sua identidade total, com ela se identifica. Todavia, essa realidade histórico-social aí se fala numa outridade que é a forma da obra, a correspondência dialética em cujo processo tal realidade, em estado de suspensão, diz-se outras. Não é por acaso que Adorno observa não ser apenas uma analogia o meio pelo qual as obras de arte refletem a violência e a dominação da realidade empírica. Assim, observa o autor, tal relação de negação e apropriação da realidade nos aspectos formais e de conteúdo dos princípios artísticos que a constituem se convertem na forma da obra.

A especificidade das obras de arte, a sua forma, não pode enquanto conteúdo sedimentado e modificado negar totalmente a sua origem. O êxito estético depende essencialmente de se o formato é capaz de despertar o conteúdo despertado na forma. Geralmente a hermenêutica das obras de arte é, pois, a transposição dos seus elementos formais em conteúdos. No entanto, estes não pertencem directamente às obras de arte como se elas recebessem simplesmente o conteúdo da realidade. $\mathrm{O}$ conteúdo constitui-se num movimento contrário. Imprime-se nas obras que dele se afastam. O progresso artístico, tanto quanto acerca dele se pode falar de modo convincente, é a totalidade desse movimento. Participa do conteúdo mediante a sua negação determinada. Quanto mais energicamente acontece, tanto mais as obras de arte se organizam segundo uma finalidade imanente e se constituem justamente assim, de modo progressivo, no contato com o que elas negam. (Adorno, 1998, p. 161)

A constatação dos princípios consumistas no processo de desenvolvimento desse tipo de sociedade industrial determina, no entanto, a "barateza dos produtos de luxo fabricados em série (...) 
evidencia que o caráter mercantil da própria arte está em vias de se modificar” (idem, ibid., p. 147), incluindo-se também entre os bens de consumo.

Tudo só tem valor na medida em que se pode trocá-lo, não na medida em que é algo em si mesmo. O valor de uso da arte, seu ser, é considerado um fetiche, e o fetiche, a avaliação social que é erroneamente entendida como hierarquia das obras de arte, torna-se seu único valor, a única qualidade que elas desfrutam. É assim que o caráter mercantil da arte se desfaz ao se realizar completamente. Ela é um gênero de mercadorias, preparadas, computadas, assimiladas à produção industrial, compráveis e fungíveis, mas a arte como um gênero de mercadorias, que vivia de ser vendida e, no entanto, de ser invendível, tão logo o negócio deixa de ser meramente sua intenção e passa a ser o seu único princípio. (Horkheimer \& Adorno, 1985, p. 148)

Mesmo a sua autonomia relativa, assegurada pelo fato de a obra artística seguir sua própria lei, negando assim o caráter mercantil da sociedade; ao longo de toda a história burguesa ela sempre esteve associada a uma autonomia tolerada. Sua condição de mercadoria, entretanto, por mais que a indústria cultural lhe imponha o status de circulação como mero valor de troca, por tantas mediações do mercado com o artista, segundo Adorno, acaba escapando, ainda que em certa medida apenas, a exigências determinadas do mercado. A falta de finalidade da obra de arte para os fins que o mercado impõe, apesar de se traduzir também nas finalidades de tal imposição como coisa desfrutável e/ou entretenimento, não reduz a grande obra de arte, entretanto, a um mero e simples objeto de consumo. A relação estabelecida com a arte requer níveis de apropriação da sua lógica interna, da lei formal que a produziu, diferentemente dos produtos culturais da indústria cultural, em que a relação é de consumo imediato.

A constatação de Adorno, na Dialética do esclarecimento, de que "a falta de finalidade da grande obra de arte moderna vive do anonimato do mercado" (idem, ibid., p. 147), resgata a condição de ambigüidade da obra de arte entre mercado e autonomia, na arte burguesa. O que lhe confere a possibilidade de negócio não é, todavia, o que lhe atribui a condição absoluta de mero valor de troca e de consumo. Se supostamente a veiculação ou o acesso, pelo barateamento, às obras de arte significasse de fato uma ascensão das massas a uma cultura dita mais elevada no sentido de emancipação e, conseqüentemente, isso estivesse representando a democratização da cultura, sempre restrita a poucos, poder-se-ia aceitar que não se 
trata de degradação, mas sim de socialização da arte. Com relação aos bens culturais tomados como a possibilidade de inserir as massas nas áreas em que antes estavam excluídas, isso significa, na avaliação de Adorno, que "a eliminação do privilégio da cultura pela venda em liquidação dos bens culturais não introduz as massas nas áreas de que eram antes excluídas, mas serve, ao contrário, nas condições existentes, justamente para a decadência da cultura e para o progresso da incoerência bárbara" (idem, ibid., p. 145).

A cooptação que a indústria cultural faz desse princípio, para inviabilizar tal exercício emancipatório mediado pela obra de arte, manipula o seu acesso e extensão social, porém jamais a verdade histórico-social que nela está mediada. Com relação à realidade, a transcendência numa obra de arte não é algo para além do real, mas uma espécie de intervenção aguda naquilo que na realidade está ocultado. Se a vulgarização estética veiculada amplamente pela indústria cultural reflete a coerção do modelo econômico que nela se oculta, a estética, num sentido mais verdadeiro e conseqüente, tomado como uma categoria do conhecimento crítico da sociedade, não é apenas um conjunto axiomático de explicação do real. Em tais circunstâncias, ela se torna uma espécie de ultrapassagem dessa imposição histórica que, embora engendre sua forma interna deixando-lhe por herança as suas contradições, é por isso mesmo sua possibilidade de transformação. Evitar que esse processo de contradição aflore e reverbere no social é a perspectiva com que a indústria cultural trata de forma alienante os conteúdos estéticos que veicula.

Tal entendimento de que, na constituição estética de uma obra de arte, os conteúdos sociais são mediados, ao interpretar-se os seus elementos constitutivos, isto é, a sua forma interna, são os conteúdos históricos que se dizem. No entanto, por não ser a obra de arte a realidade mesma, é nessa negatividade de uma relação não imediata com a empiria que as ações históricas do homem se dizem por um outro estado de reflexão. Isso equivale a dizer que o princípio de nãoidentidade da grande obra de arte - garantia da sua autonomia - é o princípio pelo qual é possível na arte um exercício de liberdade.

Neste aspecto, está contida no estético uma espécie de inconsciente histórico que, ao ser interpretado, permite um trânsito mais consciente do sujeito na apreensão do objeto ou mesmo da reciprocidade entre ambos. A arte, neste sentido, consolida-se como intercâmbio entre sujeito e objeto, exigindo o diálogo do sujeito 
com o seu outro, processo pelo qual é possível simbolizar o mundo. Não se trata, entretanto, numa concepção adorniana, de identidade entre ambos, mas de desestabilizar os princípios pelos quais a verdade só se revelaria na proeminência de um ou de outro.

A realidade que a arte pretende ser e não é confere-lhe o status de contradição por sua natureza mimética. A realidade que ela não é, no entanto, atrai pela realidade que ela re(a)presenta, isto é, o que ela diz por aquilo que é interpretada. E isso desdiz a imediaticidade da relação direta com o objeto representado para exigir do sujeito a mediação e a apropriação do recorte criativo que se estabelece no entrelaçamento dinâmico do sujeito na apreensão do objeto. Subjetividade e objetividade então se compõem como o objeto que se mostra esteticamente a exigir do sujeito que o revele como o seu outro. É nessa dimensão do estético como inconsciente histórico que, ao ser interpretado, descama linguagens outras, para além daquelas que a obra de arte negaria se a realidade se revelasse de imediato como verdade objetiva. E por que negaria é que a obra de arte tensiona constantemente o intercâmbio com a objetividade que a produz, tornando-se assim o seu conteúdo de verdade. É nessa negação tensa, todavia, que a representação da obra não é mero reflexo daquilo que está confirmado como objetividade.

Pelo fato de a perspectiva estética na obra de arte reportar-se ao real como representação e não como decodificação do objeto é que na sua constituição o objeto se dilui numa subjetividade. Pois, ao apreendê-lo, devolve-o carregado de outros códigos que desmentem a unidimensionalidade com a qual se mostra. A obra de arte torna conotativa a relação do objeto que, tensionado na sua prepotência de expressar a realidade reduzida a si mesmo, busca, no intercâmbio da subjetividade que o expressa a transgressão da unilateralidade com que pretendia manifestar-se. A dimensão metafórica remete a um contradictum daquilo que denotativamente se revelava por unicidade pragmática e, no caso, por racionalidade regressiva. A relação de interpretação da realidade altera-se, para assim compreendê-la e intervir noutras camadas possíveis.

A dimensão estética como elemento constitutivo da obra de arte não é, portanto, apenas o que viabiliza à obra sua fruição. É o componente indissociável que, ao mesmo tempo em que rouba da obra a correspondência imediata que ela pretende com a realidade, dá-lhe por excelência a condição da linguagem. A estética inviabiliza na obra qualquer transparência - o que seria a sua própria anulação 
- para traduzir nos ocultamentos que lhe são inerentes os conteúdos polissêmicos que melhor apreendem a multiplicidade de ocorrências do movimento histórico que a permeia. Nesse processo, a reflexão inaugura-se. A reflexão deve ser entendida, neste sentido, como nãoresignação e resistência do sujeito a todo clichê que envolve o plano da consciência, truncando assim a apreensão da verdade como capacidade de ação no mundo. O ocultamento, isto é, a constituição lúdica com a qual a obra redesenha expressivamente as impressóes que o seu contexto determina, surge não de maneira institucional, mas da forma arbitrária de como esteticamente o real é apreendido. É também em razão disso que as contradições sociais - material histórico - estão mediadas na obra de arte como material estético.

A relação das obras de arte com o seu conteúdo de verdade é, portanto, vivenciada num estado de extrema tensão. Ao mesmo tempo em que ela possui verdade como aparência, o seu conteúdo de verdade aparece naquilo que nega tal aparência. No seu conteúdo de verdade, como diz Adorno, a filosofia e a arte convergem, pois "a verdade da obra de arte que se desdobra progressivamente é apenas a do conceito filosófico" (Adorno, 1998, p. 151), já que a obra não é o conceito em si. Nessa semelhança de filosofia e arte é necessário perceber-se que "o conteúdo de verdade das obras não é o que elas significam, mas o que decide da verdade ou falsidade da obra em si, e só esta verdade da obra em si é comensurável à interpretação filosófica e coincide, pelo menos segundo a idéia, com a verdade filosófica" (idem, ibid.).

É necessário observar, seguindo o argumento de Adorno, que tal relação com a arte é muito difícil à consciência atual, "fixada no concreto e na imediaticidade, (...) embora sem ela não surja o conteúdo de verdade: a genuína experiência estética deve tornar-se filosofia, ou então não existe" (idem, ibid., p. 152). E é no momento de universalidade, o que a obra na sua especificação possui como linguagem sui generis, que a condição da possibilidade de convergência entre arte e filosofia deve consolidar-se, segundo o que considera Adorno. Para o autor, isto posto, revela que

Esta universalidade é coletiva, da mesma maneira que a universalidade filosófica, para a qual outrora o sujeito transcendental era o signum, remete para o sujeito coletivo. Mas, nas imagens estéticas, o seu elemento coletivo é justamente o que se subtrai ao eu: a sociedade é assim imanente ao conteúdo de verdade. O que aparece, mediante o qual a obra de arte ultrapassa de longe o puro sujeito, é a erupção da sua essência coletiva. (Idem, ibid.) 
O dado coletivo não é, porém, nas obras de arte, a separação do sujeito, mas por meio dele é que a reação coletiva se revela pelo seu movimento idiossincrático. E na perspectiva da interpretação filosófica, Adorno observa que esta deve construí-lo inviolavelmente no particular, pois, "graças ao seu momento subjetivamente mimético e expressivo, as obras de arte desembocam na sua objetividade; não são nem o puro movimento nem a sua forma, mas o processo entre ambos solidificados, e tal processo é social" (idem, ibid.).

A partir dessa interação, a obra de arte remete, assim, para um coletivo que na verdade é síntese de uma coletividade que lhe constituíra a forma. No entanto, não é só o que aparece na forma objetivamente que é o seu conteúdo de verdade, mas ao que esta forma indicia, tornando possível caminhar por suas entranhas e urdiduras através da reflexão filosófica. A objetividade aí expressa não é o que objetivamente a obra mostra. É o que nela se oculta como particularidade na sua forma de execução, condensando assim a coletividade que perpassa a singularidade da sua constituição, processo pelo qual o mundo social está mediado. A reflexão filosófica, que, por sua vez, não é a que a obra de arte é em si, é o elemento pelo qual é possível reconhecer o seu conteúdo de verdade: a universalidade que dialeticamente configura a sua condição expressiva singular como expressão social e histórica.

Quanto ao processo de mediação na obra de arte, Adorno assim se refere a essa questão: "A obra de arte é mediatizada, quanto à história real, pelo seu núcleo monadológico. A história pode chamar-se o conteúdo das obras de arte. Analisar as obras artísticas equivale a perceber a história imanente nelas armazenada" (idem, ibid., p. 103). Porém, de acordo com a afirmativa de Adorno de que nas obras de arte a objetividade e a verdade se interpenetram, não se deve perder de vista que "quanto mais profunda e totalmente as obras são formadas, tanto mais rebeldes se tornam contra a aparência organizada e esta inflexibilidade é o fenômeno negativo da sua verdade" (idem, ibid., p. 150). O sentido que a obra adquire pelo seu caráter enigmático é que ele exige da obra o seu conteúdo de verdade, ainda que não imediatamente identificável.

O que se busca a partir de tais considerações é compreender o potencial dos signos estéticos constituintes de uma obra de arte na formação do imaginário social. Importa entender de que forma o processo de massificação da cultura se tem apropriado dos elementos 
estéticos manipulativamente, não no sentido democrático da cultura para as massas, como o termo talvez possa ambiguamente sugerir.

Nessa correlação de forças que se estabelece entre estética e realidade - entre imagem e verdade social - veicula-se, no processo de massificação cultural, uma quantidade incomensurável de embotamentos sentimentais, com o fim último de solapar do indivíduo a possibilidade de consciência do processo histórico no qual se insere. A dimensão estética numa perspectiva educacional mais ampla remete, portanto, a análises categóricas tanto dos elementos constitutivos quanto formais e receptivos da expressão estética no processo de formação cultural da sociedade atual. Investigações quanto à forma de veiculação e aos usos da estética, nessa perspectiva banalizada, tornam-se imprescindíveis para resgatar o seu potencial de consciência como princípio educacional na sociedade contemporânea.

Recebido e aprovado em maio de 2003.

\section{Nota}

1. Cf. Gabriel Cohn, Theodor W. Adorno: sociologia, p. 99. Theodor Adorno reporta-se à obra Dialética do esclarecimento, escrita em conjunto com Max Horkheimer e publicada em 1947, mencionando a utilização do termo "indústria cultural" para diferenciar o caráter manipulativo da cultura imposta para as massas. No entendimento do autor, o termo "cultura de massa" poderia supor um componente de expressão popular oriundo das massas e não um processo cultural de conteúdo administrado imposto para as massas.

\section{Referências bibliográficas}

ADORNO, T.W. Palavras e sinais: modelos críticos 2. Trad. Maria Helena Ruschel. Petrópolis: Vozes, 1995.

ADORNO, T.W. Prismas: crítica cultural e sociedade. Trad. Augustin Wernet e Jorge Mattos Brito de Almeida. São Paulo: Ática, 1998.

ADORNO, T.W. Teoria estética. Trad. de Artur Morão. São Paulo: Martins Fontes, 1998.

BOTTOMORE, T. Dicionário do pensamento marxista. 2a ed. Rio de Janeiro: Zahar, 1988. 
BUCK-MORS, S. Origen de la dialéctica negativa: Theodor W. Adorno, Walter Benjamin y el Instituto de Frankfurt. México: Siglo Veintiuno, 1981.

COHN, G. Theodor W. Adorno: sociologia. 2a ed. São Paulo: Ática, 1994.

HORKHEIMER, M.; ADORNO, T.W. Dialética do esclarecimento: fragmentos filosóficos. Trad. Guido Antonio de Almeida. Rio de Janeiro: Zahar, 1985.

HORKHEIMER, M.; ADORNO, T.W. Textos escolhidos. $5^{\mathrm{a}}$ ed. São Paulo: Nova Cultura, 1991. (Os pensadores, vol. 16).

KOTHE, F.R. (Org.). Walter Benjamin: sociologia. São Paulo: Ática, 1991.

KOTHE, F.R. (Org.). Benjamin \& Adorno: confrontos. São Paulo: Ática, 1978. 